\title{
Saudi Women Information About Two Selected Contraceptive Methods in Riyadh
}

\author{
Salma Abd El Atty Moawed1, Amany Samy Badawy², Sanaa Salem Alanazi, \\ Eidah Mohammad Alharthi ${ }^{3}$ \\ ${ }^{1}$ Department of Maternity \& Child Health Nursing, College of Nursing, King Saud University, Riyadh, Kingdom of Saudi Arabia \\ ${ }^{2}$ Department of Maternal and New-born Health Nursing, College of Nursing, Zagazig University, Zagazig, Egypt \\ ${ }^{3}$ Master Student in Department of Maternity and Child Health Nursing, College of Nursing, King Saud University, Riyadh, Kingdom of \\ Saudi Arabia
}

\section{Email address:}

dramanys@hotmail.com (A. S. Badawy)

\section{To cite this article:}

Salma Abd El Atty Moawed, Amany S. Badawy, Sanaa Salem Alanazi, Eidah Mohammad Alharthi. Saudi Women Information about Two Selected Contraceptive Methods in Riyadh. American Journal of Nursing Science. Vol. 6, No. 3, 2017, pp. 261-270. doi: 10.11648/j.ajns.20170603.24

Received: March 20, 2017; Accepted: April 11, 2017; Published: May 25, 2017

\begin{abstract}
Contraception is important for reducing the rate of unplanned pregnancy in all ages, some abortions, allowing a spacing of families, and improving the health of women. Studies stressed that successfully using contraception to prevent an unplanned pregnancy is a complex undertaking that requires alignment of multiple domains: knowledge about available methods, personal attitudes and beliefs, subjective norms, and a person's ability to obtain and actually use a birth control method. Advance practice nurses in many settings can prescribe and insert contraceptive devices. The present study aimed to determine women's knowledge level regarding oral contraception pills (OCP) and intrauterine device (IUD) in Riyadh, and assessing the factors associated with this knowledge; either socio-demographic characteristics or gynecological and obstetrical history. A cross-sectional prospective study conducted among Saudi women attending ten primary care centers in Riyadh, from January to March 2016. Two hundred women participated, the women aged $\geq 18$ years who agreed to contribute to a study concerning contraception. A structured questionnaire was developed and used to compiled respondent socio-demographic, gynecological and obstetric history. It also assessed defendant's knowledge regarding oral contraceptive pills and intrauterine device. Most of the study sample (97.5\%) were educated and only (2.5\%) illiterate. About (75\%) were employees, $(23 \%)$ were bachelors. (66\%) Are using or at a point used contraceptives. Among those who used contraceptive methods, (61\%) used OCP and $(8 \%)$ used IUD. The primary source of women's knowledge regarding contraceptives was the health care team; doctor, nurse, and pharmacist. Women's average knowledge score level regarding contraceptives was relatively low; 39.85 of OCP and 33.40 of IUD. Multiple regression analysis showed that age, educational attainment, parity and use of contraceptives influencing knowledge level regarding OCP or IUD. In conclusion, oral contraceptive pills (OCP) are the most commonly used contraceptive/ than the intrauterine device (IUD) so nurses should develop more effective education about contraceptive methods.
\end{abstract}

Keywords: Saudi Women, Contraceptive Information, Oral Contraceptive Pills, Intrauterine Device

\section{Background}

Contraception is necessary for reducing the rate of unplanned pregnancy in all ages, some abortions, allowing a spacing of families, and improving the health of women [1, 2]. The introduction of oral contraceptives in the 1960s represents one of the significant advances in women's health, impacting women and society from a medical, social and political viewpoint. While, the overall health benefits of contraception and oral contraception have been well documented [3, 4, 5]. The oral contraceptive pill (OCP) provides very effective reversible contraception/ and has an excellent overall safety and tolerability profile. It is the most widely used contraceptive method [6]. 
Although intrauterine devices are the most widely used modern reversible contraceptives worldwide, with about 150 million users, they are underused because lake of knowledge and lot of misconception still linked with its use [7]. In order to achieve optimal birth spacing and ultimately to improve birth outcomes, attention should be given to contraceptive counseling and access to contraceptive methods in the postpartum period [8].

A study was carried out to identify the perception of Saudi women regarding the use of contraceptives. The results identified the low knowledge level of the participant women relating to the variety of contraceptive methods. Most members and their husbands showed acceptance to the use of contraceptives for birth spacing. They preferred birth interval of 2-3 years. When studying contraception attitudes and experiences of Saudi Arabian women; in Al-Khobar and Dammam of the eastern province. Oral contraceptive pills (OCPs) were, used by $36.6 \%$ of studied women, intra-uterine contraceptive devices (IUCD) used by $19.9 \%$, while the rest used other methods like condoms, calendar, external ejaculation, and breast- feeding [9].

In a study carried out concerning knowledge on adherence and safety of the oral contraceptive pill in Saudi women. Participants were healthy women aged $\geq 18$ years with an OCP prescription for contraception. They concluded that most Saudi women taking OCPs have limited knowledge of its correct use regarding missing pills, vomiting and diarrhea, and poor awareness of the effects of smoking while using OCPs [10], this is consistent with another study to explore the knowledge and practices of women regarding oral contraceptive utilization and to assess the factors associated with knowledge about their use. There was a significant gap in their knowledge about oral contraceptive use. In particular, women lacked knowledge about what to do after missing more than two pills consecutively or vomiting within 2 hours of taking an OCP. They also lacked knowledge about withdrawal bleeding during OCP use. They pointed out to primary health care providers; including physicians, nurses, and pharmacists, responsibility to counsel patients to understand OCP instructions [11].

Studies stressed that successfully using contraception to prevent an unplanned pregnancy is a complex undertaking that requires alignment of multiple domains: knowledge about available methods, personal attitudes and beliefs, subjective norms, and a person's ability to obtain and actually use a birth control method. In accordance, other studies remarked that Oral contraceptive (OC) knowledge deficits might contribute to OC discontinuation $[12,13]$. A woman's understanding of information related to OCs may play a critical role, directly or indirectly in facilitating or inhibiting successful OC use. Thus, it is stressed that contraception education should occur before sexual debut, should involve trusted family and community members, and should positively frame issues regarding achieving life goals [14].

Nurses often are in a position to provide information about contraception to women who are undecided about the method of contraception they want to use. The public views nurses as people who have this knowledge and are capable of taking the technical material and relaying it in terms that almost anyone can understand. Therefore, it is necessary to assess the knowledge of woman about contraception; such a study will provide a baseline data for nurses to employ in developing health education programs in maternal health care in the Kingdom. Thus, the present study aimed at determining women knowledge level regarding oral contraception pills (OCP) and intrauterine device (IUD) in Riyadh, and assessing. The factors associated with that experience; either, socio-demographic characteristics or gynecological and obstetrical history.

\section{Methods}

\subsection{Design \& Setting}

A cross-sectional prospective survey conducted between mid-February to mid-March 2016 at ten primary health care centers in North and East of Riyadh city. The ten centers were selected purposefully / because they serve the largest population inhabiting the city. The target of the present study was Saudi women aged $\geq 18$ years who agreed to participate in a study concerning contraception. A structured questionnaire was developed and used to compiled respondent socio-demographic, gynecological and obstetric history. It also assessed respondent knowledge regarding oral contraceptive pills and intrauterine device. The 23-items questionnaire was, divided into three parts. The first part included socio-demographic characteristics; like age, marital status, education level, employment, and family monthly income. The second part contains gynecological and obstetric history; like number of pregnancies, the number of delivery, the number of miscarriage, number of low birthweight babies. The third part contained questions related to contraceptive knowledge and conceptions regarding either oral contraceptive pills or intrauterine device. The last question was concerned with the source of knowledge.

\subsection{Sample \& Sampling Technique}

The researchers have been assigned to visit the health care centers periodically / and interview Saudi women who satisfy the inclusion criteria. A period of 4 weeks was the limited time to collect the samples. Throughout the period, researchers succeeded to obtain 200 sample. Researchers used to visit the centers twice a week from 8 am to $1 \mathrm{pm}$. They randomly selected a woman from each ten women attaining the center. Firstly, they introduced themselves to the woman and asked her if she was willing to participate in a study concerned contraceptives. After taking a verbal consent from the participants, the aim of the survey was, cleared, and the questionnaire explained. Then, the woman had the chance to complete and fill up the survey.

\subsection{Sampling Tools}

All questions were, written in simple Arabic language. All of the issues were, closed- ended questions, either multiple- 
choice questions or yes and no question. Questions concerned knowledge level were multiple choice question with three confined answers; Yes, No and don't know. The answers were, evaluated and a score was, given according to the correctness of the answer. The score ranged between 0 and one as follows; 1 degrees for true knowledge and 0 for wrong knowledge. The overall knowledge score has been summed up for each case and calculated in a percentage to the total corrected knowledge. Accordingly, complete knowledge has been, divided into three categories; Good $(66.6-100 \%)$, Average (33.3 - 66.6) and Poor $(0-33.3 \%)$.

\section{Results}

Table 1. Socio-Economic Characteristics of Respondent Women $(N=200)$.

\begin{tabular}{lll}
\hline Item & No. & \% \\
\hline Age Group (years) & & \\
$<20$ & 17 & 8.5 \\
$20-25$ & 52 & 26.0 \\
$26-30$ & 53 & 26.5 \\
$>30$ & 78 & 39.0 \\
$\mu \pm \sigma$ & $27.3425 \pm 4.9007$ & \\
Educational Level & & \\
Illiterate & 5 & 2.5 \\
Read \& write & 5 & 2.5 \\
Primary school & 4 & 2.0 \\
Intermediate school & 17 & 8.5 \\
Secondary school & 36 & 18.0 \\
University graduate & 133 & 66.5 \\
Employment & & \\
Housewife & 53 & 26.5 \\
Public sector employee & 93 & 46.5 \\
Private sector employee & 15 & 7.5 \\
Others & 39 & 19.5 \\
Marital Status & & \\
Bachelor & 46 & 23.0 \\
Married & 132 & 66.0 \\
Divorced & 12 & 6.0 \\
Widow & 10 & 5.0 \\
Family Income ( Saudi Riyal/Month) & & \\
$<2000$ & 49 & 32.0 \\
2000 - 6000 & 64 & \\
$6001-10000$ & 79 & \\
$>10000$ & & \\
\hline & 5.5 \\
\hline
\end{tabular}

The socio-demographic characteristics of the study sample are, shown in Table 1. The mean age of the respondents was $27.342 \pm 4.900$ years. Most of the participants (97.5\%) had received education, $66.5 \%$ had university degree while only $2.5 \%$ were non-educated. Nearly one- quarter $(26.5 \%)$ of the participants reported as housewives, and threequarters were mostly in the governmental sector (46.5\%). Most of the respondent (66\%) are married women. About one -quarter $(23.0 \%)$ are bachelorettes. Percentages of divorced and widows were about 6 and 5\%, respectively. More than one-third of the study sample (39.5\%) reported high monthly income that exceeds 10000 Saudi Riyal/month. Incomparable, about one- third of the respondents $(32.0 \%)$ reported relatively high monthly income between 6000 and 10000 Saudi Riyal/month. The rest reported a low and moderate income, 4.0 and $24.5 \%$ respectively.

Table 2. Gynecological \& Obstetric History of Respondent Women ( $N=200)$.

\begin{tabular}{|c|c|c|}
\hline Item & No. & $\%$ \\
\hline \multicolumn{3}{|c|}{ Number of Pregnancies } \\
\hline None & 57 & 28.5 \\
\hline One & 23 & 11.5 \\
\hline Two & 28 & 14.0 \\
\hline Three & 29 & 31.5 \\
\hline$>$ Three & 63 & 28.5 \\
\hline \multicolumn{3}{|c|}{ Number of Deliveries } \\
\hline None & 61 & 31.5 \\
\hline One & 25 & 12.5 \\
\hline Two & 33 & 16.5 \\
\hline Three & 26 & 13.0 \\
\hline$>$ Three & 55 & 27.5 \\
\hline \multicolumn{3}{|c|}{ Number of Miscarriages } \\
\hline None & 138 & 69.0 \\
\hline One & 39 & 19.5 \\
\hline$>$ One & 23 & 11.5 \\
\hline \multicolumn{3}{|c|}{ Number of Babies Born Alive } \\
\hline None & 62 & 32.0 \\
\hline One & 27 & 13.5 \\
\hline Two & 31 & 15.5 \\
\hline Three & 28 & 14.0 \\
\hline$>$ Three & 52 & 26.0 \\
\hline \multicolumn{3}{|c|}{ Number of Babies Born Dead } \\
\hline None & 169 & 84.5 \\
\hline One & 22 & 11.0 \\
\hline Two & 4 & 2.0 \\
\hline Three & 3 & 1.5 \\
\hline$>$ Three & 2 & 1.0 \\
\hline \multicolumn{3}{|c|}{ Number of Low Birth Weight Babies } \\
\hline None & 140 & 70.0 \\
\hline One & 37 & 18.5 \\
\hline Two & 11 & 5.5 \\
\hline Three & 7 & 3.5 \\
\hline$>$ Three & 5 & 2.5 \\
\hline
\end{tabular}

Table 2 summarized the gynecological and obstetric history of the respondent women. Regarding the number of previous pregnancies, about one -thirds of the interviewees $(28.5 \%)$ have never been pregnant before. More than half of the sampled women $(60 \%)$ were pregnant for three times and more. Concerning the number of deliveries, percentages are comparable to that of some pregnancies, and the differences attributed to the number of miscarriage. The rate of abortion among the respondent; either once or more, reached about $31.0 \%$. Percentage of women who had babies reached $69.5 \%$ compared to $15.5 \%$ of the interviewees had bad experiences of giving birth to a dead baby. Low-birth- weight was, reported with $30 \%$ of the respondent women; either once or several times.

Table 3. Family Planning \& Contraceptive Use Information of Respondent Women $(N=200)$.

\begin{tabular}{lll}
\hline Item & No. & $\mathbf{\%}$ \\
\hline Ideal Inter-pregnancies Intervals (Years) & & \\
$<$ One & 13 & 6.5 \\
$1-2$ & 40 & 20.2 \\
$2-3$ & 105 & 52.5 \\
$>$ Three & 42 & 21.0 \\
Short Inter-pregnancies Interval affect fetus & & \\
Yes & 63 & 31.5 \\
\hline
\end{tabular}




\begin{tabular}{|c|c|c|}
\hline Item & No. & $\%$ \\
\hline \multicolumn{3}{|c|}{ Ideal Inter-pregnancies Intervals (Years) } \\
\hline$<$ One & 13 & 6.5 \\
\hline $1-2$ & 40 & 20.2 \\
\hline $2-3$ & 105 & 52.5 \\
\hline$>$ Three & 42 & 21.0 \\
\hline \multicolumn{3}{|c|}{ Short Inter-pregnancies Interval affect fetus } \\
\hline Yes & 63 & 31.5 \\
\hline No & 70 & 35.0 \\
\hline I don’t know & 67 & 33.5 \\
\hline \multicolumn{3}{|c|}{ Short Inter-pregnancies Interval affect childhood } \\
\hline Yes & 70 & 35.0 \\
\hline No & 63 & 31.5 \\
\hline I don’t know & 67 & 33.5 \\
\hline \multicolumn{3}{|c|}{ Short Inter-pregnancies Interval affect maternal } \\
\hline Yes & 128 & 64.0 \\
\hline No & 28 & 14.0 \\
\hline I don’t know & 44 & 22.0 \\
\hline \multicolumn{3}{|c|}{ Support family planning \& contraceptive use } \\
\hline Yes & 170 & 85.0 \\
\hline No & 30 & 15.0 \\
\hline \multicolumn{3}{|l|}{ Use contraceptive } \\
\hline Yes & 132 & 66.0 \\
\hline No & 68 & 34.0 \\
\hline \multicolumn{3}{|l|}{ Type of contraceptive used } \\
\hline None & 68 & 34.0 \\
\hline Oral Contraceptive Pills & 80 & 40.0 \\
\hline Intrauterine Device & 11 & 5.5 \\
\hline Cervical caps or diaphragm & 3 & 1.5 \\
\hline Folk medicine contraceptives & 3 & 1.5 \\
\hline Skin patches (Hormonal Patches) & 3 & 1.5 \\
\hline Injections & 2 & 1.0 \\
\hline Male condom & 6 & 3.0 \\
\hline Several methods & 24 & 12.0 \\
\hline
\end{tabular}

Dealing with family planning concept and contraceptive used among respondent women, Table 3 described their responses. A Considerable percentage of the interviewees $(73.5 \%)$ indicated that the idea of the ideal inter-pregnancies interval (IPI) is between 2 and three years or more. On the other hand, $26.5 \%$ of the respondents showed that perfect inter-pregnancies interval (IPI) is between 1 and two years or less. In average, the results indicated that ideal inter-pregnancies interval for the sampled women is $2.038 \pm 0.582$ years. Surprisingly, only about one- third of the respondents stated that short inter-pregnancies interval affects either the fetus or the childhood. On contrast, a considerable percentage of the interviewees $(64.0 \%)$ agreed that short inter-pregnancies interval affects maternal health. Most of the respondent women (85.0\%) supported family planning. Among the respondent women, $66 \%$ are using and ever use contraceptives.

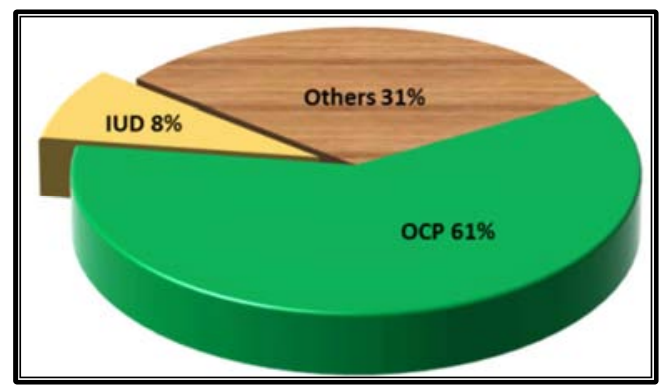

Figure 1. Percentage of Contraceptive Methods Used among Respondent Women.
Figure 1 showed that oral contraceptive pills (OCP) are the most commonly used contraceptive (61\%) while using an intrauterine device (IUD) was common only among $8 \%$ of the respondents. About one-third of the respondent women $(31.0 \%)$ used other methods, like; cervical cap, folk medicine, skin patches, injections, male condom or more than one method.

Table 4. Knowledge Regarding Oral Contraceptive Pills (OCP) of Respondent Women $(N=200)$.

\begin{tabular}{|c|c|c|c|}
\hline Item & Right & Wrong & $\begin{array}{l}\text { I Don't } \\
\text { Know }\end{array}$ \\
\hline OCP suitable for all women & 121 & 45 & 34 \\
\hline $\begin{array}{l}\text { OCP proper mother is appropriate for } \\
\text { daughter }\end{array}$ & 105 & 16 & 79 \\
\hline $\begin{array}{l}\text { All OCP have the same formula with } \\
\text { different brand names }\end{array}$ & 63 & 71 & 66 \\
\hline $\begin{array}{l}\text { For a better result, sexual abstinence } \\
\text { for one week before OCP use }\end{array}$ & 44 & 48 & 108 \\
\hline $\begin{array}{l}\text { OCP work best when taken the same } \\
\text { time each day }\end{array}$ & 134 & 19 & 47 \\
\hline OCP regulate menstrual cycles & 128 & 23 & 49 \\
\hline $\begin{array}{l}\text { OCP containing both Estrogen \& } \\
\text { Progestin hormone }\end{array}$ & 39 & 21 & 140 \\
\hline Efficiency of OCP reaches $95-98 \%$ & 113 & 21 & 66 \\
\hline $\begin{array}{l}\text { OCP containing Progestin hormone } \\
\text { only }\end{array}$ & 31 & 26 & 143 \\
\hline OCP increase the risk of breast cancer & 84 & 18 & 98 \\
\hline OCP cause weight gain (obesity) & 119 & 28 & 53 \\
\hline OCP raise blood pressure & 96 & 19 & 85 \\
\hline OCP cause depression \& mood changes & 144 & 8 & 48 \\
\hline $\begin{array}{l}\text { OCP is not suitable for women with } \\
\text { breast cancer }\end{array}$ & 75 & 16 & 109 \\
\hline OCP is not suitable for diabetic women & 54 & 30 & 116 \\
\hline $\begin{array}{l}\mathrm{OCP} \text { is suitable for women with heart } \\
\text { disease }\end{array}$ & 33 & 52 & 115 \\
\hline $\begin{array}{l}\text { OCP is suitable for women with blood } \\
\text { clots (venous thromboembolism) }\end{array}$ & 42 & 50 & 108 \\
\hline $\begin{array}{l}\text { OCP is suitable for women with kidney } \\
\text { disease }\end{array}$ & 38 & 45 & 117 \\
\hline $\begin{array}{l}\text { OCP is suitable for women with liver } \\
\text { disease }\end{array}$ & 33 & 46 & 121 \\
\hline
\end{tabular}

*Cells contained correct response shaded

Table 4 shown sampled women replies of questions on knowledge regarding oral contraceptive pills (OCP). The questionnaire includes 19 question concerned facts and conceptions about oral contraceptive nature, use, side effects, and suitability. The highest percentage of right answers were that concerned with regular time for taking the daily pill, and that concerning pills regulate the menstrual cycle. The former question got $67 \%$ of the right answers while the latter have $64 \%$ of the right answers. On the contrary, the lowest percentage of correct answers were that concerned that pills containing progestin hormone only and the question that OCP suitable for the woman with heart disease. The first issue got $15.5 \%$ of right answers, while that second issue got $16.5 \%$ of correct answers. 
Table 5. Knowledge Regarding Symptoms Dictate Stop Taking Oral Contraceptive Pills (OCP) of Respondent Women $(N=200)$.

\begin{tabular}{llll}
\hline Item & Right & Wrong & $\begin{array}{l}\text { I Don't } \\
\text { Know }\end{array}$ \\
\hline Stop taking OCP if feeling chest pain & 86 & 25 & 89 \\
Stop taking OCP if feeling leg pain & 78 & 27 & 95 \\
Stop taking OCP if feeling liver pain & 92 & 16 & 92 \\
Stop taking OCP if feeling blurred vision & 82 & 25 & 93 \\
Stop taking OCP if feeling a migraine & 79 & 34 & 87 \\
\hline
\end{tabular}

*Cells contained correct response shaded
Sampled women replies of questions on knowledge regarding oral contraceptive pills (OCP) are, shown in the Table 5. The questionnaire includes 5 question concerned symptoms dictate stop taking the pills. The right answers percentages for the five questions varied between 39 and $46 \%$. The percentages of correct answers are relatively small with an average of $41.3 \%$.

Table 6. Knowledge Regarding Intrauterine Device (IUD) of Respondent Women (N=200).

\begin{tabular}{llll}
\hline Item & Right & Wrong & I Don't Know \\
\hline IUD is advised for women who had previous pregnancy and childbirth & 140 & 16 & 80 \\
There are several types of IUD & 112 & 13 & 75 \\
IUD success depends on atrophy of the uterine mucous membrane \& change cervical secretion & 39 & 12 & 149 \\
Mirena is a plastic IUD that helps in the progesterone secretion & 9 & 32 & 159 \\
IUD increases menstrual bleeding for the first six months of use & 82 & 16 & 102 \\
IUD causes lower back pain & 93 & 17 & 90 \\
IUD may perforate the uterus & 21 & 46 & 133 \\
IUD efficiency in birth control reaches 95\% & 77 & 37 & 86 \\
IUD side effects is lower than that of OCP & 81 & 18 & 101 \\
\hline
\end{tabular}

*Cells contained correct response shaded

Table 6 shows sampled women replies on questions about knowledge regarding intrauterine device (IUD). The questionnaire includes 9 question concerned facts and conceptions about intrauterine device nature, use, side effects, and suitability. The highest percentage of right answers were that concerned with an advice of using IUD for a woman who had pregnant and got childhood and that about the presence of several types of IUD. The first question got $70 \%$ of the right answers while the second have $56 \%$ of the right answers. On the contrary, the lowest percentage of correct answers were that concerned with the plastic IUD "MIRENA" and the conception that IUD may perforate the uterus. The former question got $4.5 \%$ of the right answers, while the latter question got $11.5 \%$ of correct answers. In general, a percentage of the correct answers for other issue varied, but not exceed $46 \%$.

Table 7. Knowledge Regarding Proper Time for Insertion the Intrauterine Device (IUD) of Respondent Women $(N=200)$.

\begin{tabular}{lll}
\hline Timing & YES & $\mathbf{\%}$ \\
\hline During the menstrual cycle & 31 & 15.5 \\
Last day of menstrual cycle & 33 & 16.5 \\
Six weeks after the normal delivery & 15 & 7.5 \\
Three months after cesearen surgery & 4 & 2.0 \\
Don't Know & 117 & 58.5 \\
\hline
\end{tabular}

*Cells contained correct response shaded

Concerning proper time for intrauterine device insertion, responses of sampled women are, shown in the Table 7. More than half of the tested women (58.5\%) didn't know the proper time. $16.5 \%$ of the women wrongly chose the last day of menstrual cycle. The percentage of women who chose correct answer was relatively low, only one-quarter of the women.

Table 8. Source of Knowledge Regarding Contraceptives for Respondent Women $(N=200)$.

\begin{tabular}{lll}
\hline Source & YES & \%* $^{*}$ \\
\hline Doctor & 145 & 72.5 \\
Nurse & 23 & 11.5 \\
Pharmacist & 11 & 5.5 \\
Relatives & 49 & 24.5 \\
Friends & 31 & 15.5 \\
School & 6 & 3.0 \\
Television \& Radio & 11 & 5.5 \\
Newspapers \& Magazines & 17 & 8.5 \\
Internet & 43 & 21.5 \\
\hline
\end{tabular}

*Percentage exceeds $100 \%$ because for some respondents there were multiple sources of information

Different sources of sampled women's knowledge regarding contraceptives summarized in Table 8 . The primary source of women's knowledge was the health care team; doctor, nurse, and pharmacist. Doctors represent the source of knowledge for about three quarter $(72.5 \%)$ of respondent women, nurses represented the source of awareness for $11.5 \%$, while pharmacist was the source of knowledge of $5.5 \%$ of the sampled women. In the second rank family members $(24.5 \%)$ and friends $(15.5 \%)$. The Internet represents the source of knowledge regarding contraceptives for $21.5 \%$ of the respondent. The contribution of press media, television and radio media and school curriculum contributed as a source of knowledge regarding contraceptive for respondent women with relatively insignificant percentages; 
$8.8 \%, 5.5 \%$, and $3.0 \%$, respectively. Knowledge score regarding oral contraceptive pills (OCP) for respondent women varied between 0 and $91.667 \%$, with an average of $39.854 \pm 22.834$.

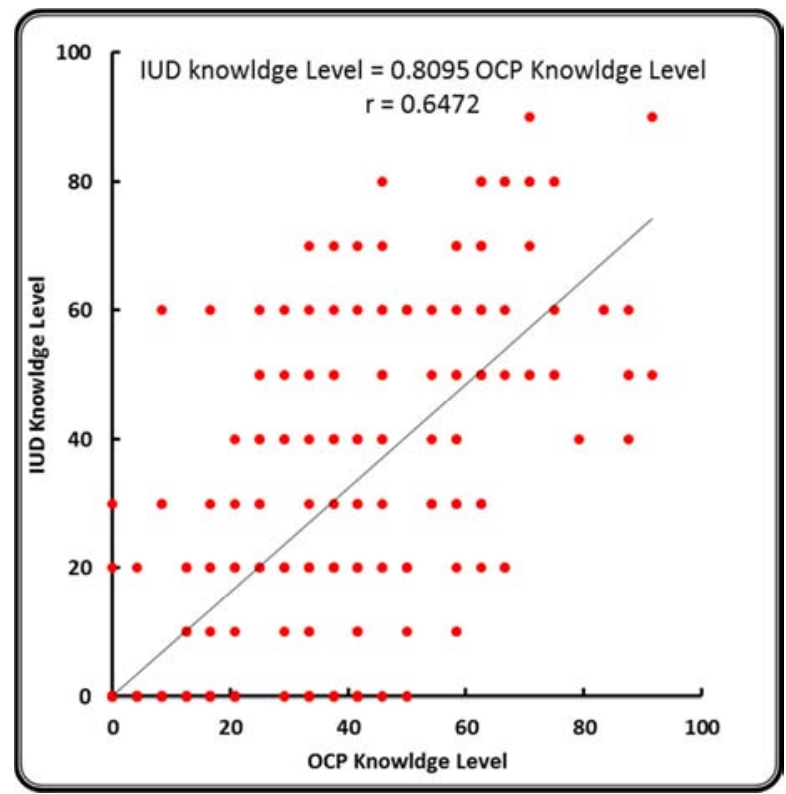

Figure 2. Correlation \& Ratio between OCP Knowledge Score Level \& IUD Knowledge Score Level among Respondent Women.

The relation between OCP knowledge score level and IUD knowledge score level among sampled women illustrated in figure (2). The results indicated that correlation coefficient between the two scores is 0.6472. Regarding ratio, IUD knowledge score level is equal to about 0.809 OCP knowledge score level among respondent women, i.e. among sampled women, OCP knowledge score level is always higher than IUD knowledge score level with about $20 \%$.

Table 9. Relation between Socio-Economic Characteristics \& Knowledge Level Regarding Oral Contraceptive Pills (OCP) among Respondent Women.

\begin{tabular}{|c|c|c|c|c|c|}
\hline \multirow{2}{*}{ Item } & \multicolumn{3}{|c|}{ Knowledge Level } & \multirow{2}{*}{$\mathbf{X}^{2}$} & \multirow{2}{*}{ P Value } \\
\hline & Poor & Fair & Good & & \\
\hline \multicolumn{6}{|l|}{ Age group (Years) } \\
\hline$<20$ & 9 & 6 & 2 & \multirow{4}{*}{19.464} & \multirow{4}{*}{$0.006 * *$} \\
\hline $20-25$ & 34 & 18 & 0 & & \\
\hline $26-30$ & 14 & 31 & 8 & & \\
\hline$>30$ & 26 & 42 & 10 & & \\
\hline \multicolumn{6}{|l|}{ Educational Level } \\
\hline Up to intermediate level & 5 & 9 & 0 & \multirow[t]{3}{*}{1.102} & \multirow[t]{3}{*}{0.293} \\
\hline Secondary school and above & 78 & 88 & 20 & & \\
\hline Marital Status & & & & & \\
\hline Bachelor & 33 & 11 & 2 & \multirow{4}{*}{21.570} & \multirow{4}{*}{$0.028^{*}$} \\
\hline Married & 41 & 74 & 17 & & \\
\hline Divorced & 4 & 7 & 1 & & \\
\hline Widowed & 5 & 5 & 0 & & \\
\hline \multicolumn{6}{|l|}{ Employment } \\
\hline Housewife & 22 & 27 & 4 & \multirow[t]{3}{*}{0.212} & \multirow[t]{2}{*}{0.644} \\
\hline Employed & 61 & 70 & 16 & & \\
\hline \multicolumn{5}{|l|}{ Family Income } & \\
\hline$\leq 6000 /$ month & 22 & 32 & 3 & \multirow[t]{2}{*}{2.018} & \multirow[t]{2}{*}{0.1554} \\
\hline$\geq 6000 /$ month & 61 & 65 & 17 & & \\
\hline
\end{tabular}

*Significant level at $0.05, * *$ High significant level 0.001
The previous table summarizes the relation between socioeconomic variables and oral contraceptive pills (OCP) knowledge score level for sampled women. Five sociodemographic variables have been, elected; age, educational attainment, marital status, employment and family income. Regarding women's age, statistical analysis showed a highly significant difference in women's knowledge score level on her age, where $\chi^{2}$ was 19.464 with $\mathrm{P}$-value $<0.0006$. Indicated that knowledge score level regarding OCP increases with age. About women's educational attainment, this factors didn't play a role regarding OCP knowledge score level. It is worthily mentioning that most of the sampled women were highly educated. Concerning marital status, the statistical analysis showed a highly significant difference in women's knowledge score level regarding OCP. It is evident that married women more knowledgeable, where $\chi^{2}$ was 21.5702 with P-value $<0.001$. About employment, statistical analysis did not reveal any significant difference of knowledge score level regarding OCP between employed and non-employed women. In accordance, family income does not influence the women's knowledge score level regarding OCP. (Table 9)

Table 10. Relation between Gynecological \& Obstetric History \& Knowledge Level Regarding Oral Contraceptive Pills (OCP) among Respondent Women.

\begin{tabular}{|c|c|c|c|c|c|}
\hline \multirow{2}{*}{ Item } & \multicolumn{3}{|c|}{ Knowledge Level } & \multirow{2}{*}{$\mathbf{X}^{2}$} & \multirow{2}{*}{ P Value } \\
\hline & Poor & Fair & Good & & \\
\hline \multicolumn{6}{|c|}{ Number of Pregnancies } \\
\hline None & 37 & 17 & 3 & \multirow{5}{*}{17.489} & \multirow{5}{*}{$0.0016^{* *}$} \\
\hline One & 9 & 13 & 1 & & \\
\hline Two & 7 & 17 & 4 & & \\
\hline Three & 8 & 18 & 3 & & \\
\hline$>$ Three & 22 & 32 & 9 & & \\
\hline \multicolumn{4}{|c|}{ Number of Deliveries } & \multirow{6}{*}{25.979} & \multirow{6}{*}{$0.0052 *$} \\
\hline None & 40 & 18 & 3 & & \\
\hline One & 9 & 15 & 1 & & \\
\hline Two & 7 & 19 & 7 & & \\
\hline Three & 5 & 19 & 2 & & \\
\hline$>$ Three & 22 & 26 & 7 & & \\
\hline \multicolumn{4}{|c|}{ Number of Miscarriages } & \multirow{4}{*}{0.896} & \multirow{4}{*}{0.638} \\
\hline None & 61 & 64 & 13 & & \\
\hline One & 13 & 20 & 6 & & \\
\hline$>$ One & 9 & 13 & 1 & & \\
\hline \multicolumn{4}{|c|}{$\begin{array}{l}\text { Number of Low Birth } \\
\text { Weight Babies }\end{array}$} & \multirow{6}{*}{3.223} & \multirow{6}{*}{0.199} \\
\hline None & 62 & 62 & 16 & & \\
\hline One & 12 & 23 & 2 & & \\
\hline Two & 4 & 6 & 1 & & \\
\hline Three & 3 & 4 & 0 & & \\
\hline$>$ Three & 2 & 2 & 1 & & \\
\hline \multicolumn{4}{|c|}{ Use of Contraception } & \multirow{3}{*}{16.024} & \multirow{3}{*}{0.2831} \\
\hline Yes & 41 & 74 & 17 & & \\
\hline No & 42 & 23 & 3 & & \\
\hline
\end{tabular}

*Significant level at $0.05, * *$ High significant level 0.001

Table 10 shows the statistical analysis to determine the relation between the gynecological and obstetric history of respondent women and her knowledge score level regarding oral contraceptive OCP. Five different variables concerning 
gynecological and obstetric history have been, selected; the number of pregnancies, the number of deliveries, the number of miscarriages, some low birthweight babies and finally using contraceptives. Some pregnancies and number of births were, highly contributed to women's knowledge score level regarding OCP. For some pregnancies, $\chi^{2}$ was 17.4894 with P-value < 0.0016 , while for the number of deliveries, $\chi^{2}$ was 25.9794 with $\mathrm{P}$-value $<0.000001$. Indicated that party plays a significant role in raising knowledge regarding OCP. In contrast, statistical analysis showed that women using contraceptives were more knowledgeable than those don't use contraceptives. $\chi^{2}$ was 16.024 with $\mathrm{P}$-value $<0.0006$. On the other hand, some miscarriages and number of low birthweight babies did not show any significant difference with women's knowledge score level regarding OCP.

Table 11. Relation between Socio-Economic Characteristics \& Knowledge Level Regarding Intrauterine Device (IUD) among Respondent Women.

\begin{tabular}{|c|c|c|c|c|c|}
\hline \multirow{2}{*}{ Item } & \multicolumn{3}{|c|}{ Knowledge Level } & \multirow{2}{*}{$\mathbf{X}^{2}$} & \multirow{2}{*}{ P Value } \\
\hline & Poor & Fair & Good & & \\
\hline \multicolumn{6}{|l|}{ Age group (Years) } \\
\hline$<20$ & 11 & 1 & 5 & \multirow{4}{*}{27.862} & \multirow{4}{*}{$0.0038^{* *}$} \\
\hline $20-25$ & 42 & 7 & 3 & & \\
\hline $26-30$ & 24 & 21 & 8 & & \\
\hline$>30$ & 32 & 38 & 8 & & \\
\hline \multicolumn{6}{|l|}{ Educational Level } \\
\hline Up to intermediate level & 10 & 2 & 2 & \multirow[t]{3}{*}{1.613} & \multirow[t]{2}{*}{0.204} \\
\hline Secondary school and above & 99 & 65 & 22 & & \\
\hline \multicolumn{5}{|l|}{ Marital Status } & \\
\hline Bachelor & 39 & 5 & 2 & \multirow{4}{*}{21.366} & \multirow{4}{*}{$0.0023 * *$} \\
\hline Married & 58 & 54 & 20 & & \\
\hline Divorced & 5 & 5 & 2 & & \\
\hline Widowed & 7 & 3 & 0 & & \\
\hline \multicolumn{6}{|l|}{ Employment } \\
\hline Housewife & 22 & 27 & 4 & \multirow[t]{2}{*}{0.2129} & \multirow[t]{2}{*}{0.6445} \\
\hline Employed & 61 & 70 & 16 & & \\
\hline \multicolumn{6}{|l|}{ Family Income } \\
\hline$\leq 6000 /$ month & 31 & 14 & 12 & \multirow[t]{2}{*}{7.345} & \multirow[t]{2}{*}{$0.0254 *$} \\
\hline$\geq 6000 /$ month & 78 & 53 & 12 & & \\
\hline
\end{tabular}

*Significant level at $0.05, * *$ High significant level 0.001

Table 11 summarize the relation between socio-economic variables and intrauterine device (IUD) knowledge score level for sampled women. For consistency, the same five sociodemographic variables elected; age, educational attainment, marital status, employment and family income. Similar to the case of OCP, women's age, and marital status the two factors which related to women's knowledge score level regarding IUD. For -age, statistical analysis showed a highly significant difference in women's knowledge score level concerning her age, where $\chi^{2}$ was 27.8623 with P-value $<0.000001$. Also, this indicated that knowledge score level regarding IUD increase with age. Concerning marital status, the statistical analysis showed a highly significant difference in women's knowledge score level regarding IUD. It is also evident that married women more knowledgeable, where $\chi^{2}$ was 21.3663 with P-value < 0.00002. On the other hand, educational attainment, employment, and family income didn't show any significant difference with women's knowledge regarding IUD.
Table 12. Relation between Gynecological \& Obstetric History \& Knowledge Level Regarding Intrauterine Device (IUD) among Respondent Women.

\begin{tabular}{|c|c|c|c|c|c|}
\hline \multirow{2}{*}{ Item } & \multicolumn{3}{|c|}{ Knowledge Level } & \multirow{2}{*}{$\mathbf{X}^{2}$} & \multirow{2}{*}{ P Value } \\
\hline & Poor & Fair & Good & & \\
\hline \multicolumn{4}{|c|}{ Number of Pregnancies } & \multirow{6}{*}{27.483} & \multirow{6}{*}{$0.0012 * *$} \\
\hline None & 46 & 7 & 4 & & \\
\hline One & 15 & 5 & 3 & & \\
\hline Two & 10 & 12 & 6 & & \\
\hline Three & 10 & 13 & 6 & & \\
\hline$>$ Three & 28 & 30 & 5 & & \\
\hline \multicolumn{4}{|c|}{ Number of Deliveries } & \multirow{6}{*}{34.273} & \multirow{6}{*}{$0.0029 * *$} \\
\hline None & 51 & 6 & 4 & & \\
\hline One & 13 & 8 & 4 & & \\
\hline Two & 10 & 17 & 6 & & \\
\hline Three & 7 & 13 & 6 & & \\
\hline$>$ Three & 28 & 23 & 4 & & \\
\hline \multicolumn{4}{|c|}{ Number of Miscarriages } & \multirow{4}{*}{2.458} & \multirow{4}{*}{0.292} \\
\hline None & 78 & 40 & 20 & & \\
\hline One & 18 & 17 & 4 & & \\
\hline$>$ One & 13 & 10 & 0 & & \\
\hline \multicolumn{4}{|c|}{$\begin{array}{l}\text { Number of Low Birth } \\
\text { Weight Babies }\end{array}$} & \multirow{6}{*}{1.595} & \multirow{6}{*}{0.4503} \\
\hline None & 75 & 49 & 16 & & \\
\hline One & 22 & 10 & 5 & & \\
\hline Two & 5 & 5 & 1 & & \\
\hline Three & 4 & 1 & 2 & & \\
\hline$>$ Three & 3 & 2 & 0 & & \\
\hline \multicolumn{4}{|c|}{ Use of Contraception } & \multirow{3}{*}{22.005} & \multirow{3}{*}{$0.0031 * *$} \\
\hline Yes & 57 & 58 & 17 & & \\
\hline No & 52 & 9 & 7 & & \\
\hline
\end{tabular}

**High significant level 0.001

The statistical analysis to determine the relation between the gynecological and obstetric history of respondent women and her knowledge (Table 12) score level regarding oral contraceptive IUD. Selected variables concerning gynecological and obstetric history were; the number of pregnancies, number of deliveries, the number of miscarriages, number of low birthweight babies and finally using contraceptives. By results concerning OCP knowledge, the number of pregnancies, the number of deliveries and use of contraceptives was, highly contributed to women's knowledge score level regarding IUD. For number of pregnancies, $\chi^{2}$ was 27.483 with $\mathrm{P}$-value $<0.0012$, for number of deliveries, $\chi^{2}$ was 34.2732 with $\mathrm{P}$-value < 0.000002 , while for using contraceptives, $\chi^{2}$ was 22.005 with $\mathrm{P}$-value $<0.0002$. Again, this indicated that parity and using contraceptives play an important role in raising knowledge regarding IUD. On the other hand. On the other hand, some miscarriages and number of low birthweight babies did not show any significant difference with women's knowledge score level regarding IUD.

Table 13. Multiple Regression Analysis of Socio-Economic \& Gynecological \& Obstetric History Factors Associated with Knowledge Level Regarding Oral Contraceptive Pills (OCP) among Respondent Women.

\begin{tabular}{lccc}
\hline Item & Coefficient & t-Statistic & P-value \\
\hline Knowledge Level Regarding OCP vs. Socio-economic Characteristics \\
Age & 8.228 & 5.167 & 0.058 \\
Education Level & 3.364 & 2.362 & 0.019 \\
Employment & -1.385 & -0.747 & 0.455 \\
\hline
\end{tabular}




\begin{tabular}{llll}
\hline Item & Coefficient & t-Statistic & P-value \\
\hline Family Income & -0.126 & -0.064 & 0.948 \\
& $(\mathrm{t}=25.2581 \quad \& \quad \mathrm{P}<0.00001)$ \\
Knowledge Level Regarding OCP vs. Gynecological \& Obstetric \\
Characteristics \\
Number of Pregnancies & 9.538 & 2.234 & 0.026 \\
Number of Deliveries & -1.913 & -0.474 & 0.636 \\
Number of Miscarriages & -4.944 & -1.1621 & 0.106 \\
Number of low birthweights & -3.001 & -1.320 & 0.188 \\
Use of Contraceptives & 28.032 & 6.020 & 0.8204 \\
& $(\mathrm{t}=18.1690 \& \mathrm{P}<0.00001)$ \\
\hline
\end{tabular}

Multiple regression analysis between socio-economic and gynecological and obstetric history variable against knowledge score level regarding OCP have been applied (Table 13). For socio-economic characteristics as explanatory variables, degree of association $(\mathrm{r})$ was highly significant $(\mathrm{t}=$ 25.2581, P-value $<0.000001)$. The coefficient of determination $\left(\mathrm{r}^{2}\right)$ indicated that the four socio-demographic characteristics (age, educational level, employment and family income) within the model was able to explain $76.3 \%$ of the variations in the dependent variable (knowledge score level regarding OCP). In sum, it was, shown that age and educational attainment were the most important variables in the model. Means that women's knowledge level regarding OCP influenced by age and level of education, rather than employment and family income. For gynecological and obstetric history variable as explanatory variables, degree of association $(\mathrm{r})$ was highly significant $(\mathrm{t}=18.169$, P-value < $0.000001)$. Coefficient of measurement $\left(\mathrm{r}^{2}\right)$ showed that, the five gynecological and obstetric history variable (number of pregnancies, number of deliveries, number of miscarriage, number of low birthweights and using contraceptives) in the model was, able to explain $67.3 \%$ of the differences in the dependent variable (knowledge score level regarding OCP). In sum, it was shown that number of pregnancies and using contraceptives were the most important variables in the model. That means that women's knowledge level regarding OCP is affected by parity and experience in using contraceptives.

Table 14. Multiple Regression Analysis of Socio-Economic \& Gynecological \& Obstetric History Factors Associated with Knowledge Level Regarding Intrauterine Device (IUD) among Respondent Women.

\begin{tabular}{llcc}
\hline Item & Coefficient & t-Statistic & P-value \\
\hline Knowledge Level Regarding IUD vs. Socio-economic Characteristics \\
Age & 6.2542 & 3.6192 & 0.0004 \\
Education Level & 5.6501 & 3.6568 & 0.0003 \\
Employment & -5.8895 & -2.9281 & 0.0038 \\
Family Income & -1.0523 & -0.4958 & 0.6206 \\
\multicolumn{4}{|c}{} \\
Knowledge Level Regarding OCP vs. Gynecological \& Obstetric \\
Characteristics & \multicolumn{4}{c}{} \\
Number of Pregnancies & 10.6927 & 2.5585 & 0.0113 \\
Number of Deliveries & -3.6814 & -0.9315 & 0.3527 \\
Number of Miscarriages & -2.8452 & -0.9532 & 0.3417 \\
Number of low birthweights & -3.8417 & -1.7258 & 0.0860 \\
Use of Contraceptives & 23.1417 & 5.0760 & 0.7906 \\
& $(\mathrm{t}=21.0335-\mathrm{P}<0.00001)$ \\
\hline
\end{tabular}

Multiple regression analysis between socio-economic and gynecological and obstetric history variable against knowledge score level regarding IUD summarized in (Table 14). For socio-economic characteristics as explanatory variables, degree of association $(\mathrm{r})$ was highly significant $(\mathrm{t}=$ 19.88, P-value $<0.00001)$. The coefficient of determination $\left(\mathrm{r}^{2}\right)$ indicated that the four socio-demographic characteristics (age, educational level, employment and family income) within the model was able to explain $66.6 \%$ of the variations in the dependent variable (knowledge score level regarding IUD). In general, it was, revealed that age, educational attainment, and employment were the most important variables in the model. Means that women's knowledge level regarding IUD is influenced by age, educational attainment, and employment, rather than family income.

For gynecological and obstetric history variable as explanatory variables, degree of association (r) was highly significant $(\mathrm{t}=21.0335$, P-value $<0.000001)$. Coefficient of measurement $\left(\mathrm{r}^{2}\right)$ indicated that, the five gynecological and obstetric history variables, (number of pregnancies, number of deliveries, number of miscarriage, number of low birthweights and using contraceptives) within the model was able to explain $62.5 \%$ of the variations in the dependent variable (knowledge score level regarding IUD). Accordingly, the number of pregnancies, some low birthweight babies, and using contraceptives were the most important variables in the model. In agreement with the previous finding, women's knowledge level regarding IUD influenced by parity and experience in using contraceptives.

\section{Discussion}

Contraception is essential for reducing the rate of unplanned pregnancy in all ages, some abortions, allowing the spacing of families, and improving the health of women $[2,15]$. The oral contraceptive pill (OCP) provides very effective reversible contraception and has an excellent overall safety and tolerability profile. On the other hand, the intrauterine device (IUD) is an ideal postpartum method because it does not interfere with lactation, facilitates adequate birth spacing and does not require repeat health care visits for contraceptive refills.

In the present study, Average age of the respondents was $27.342 \pm 4.900$ years. That is comparable with all studies carried out in Saudi Arabia because that is the average age for a fertile woman. Also, most of the participants (97.5\%) were, educated, while $66.5 \%$ had a university degree. Concerning employment, nearly three quarters are working; mostly in the governmental sector (46.5\%). Most of the respondent $(66 \%)$ are married women. About one-quarter $(23.0 \%)$ are bachelors. The result of the present study revealed that sampled women had poor knowledge score and awareness about O. C. P. especially the question regarding absolute and relative contraindication such as liver, heart disease, DM, kidney... etc. in spite of that these diseases are very common in Saudi Arabia. Also, early marriage $(<20$ years) is still common in different cities around the Kingdom [16].

Moreover, the percentage of the right answers regarding 
intrauterine devices (IUD) did not exceed 46\%. On the other hand, there is a highly significant relationship between their knowledge about O. C. P. Their age \& marital relation has no significant association between level of education, family income \& employment status, the same implied found by other researches on the same topic [10, 17, 18]. Education level, employment, and age play an important variable on women's knowledge level rather than family income. Also, the knowledge level regarding IUD influenced by parity \& experience in using contraception. So, the primary healthcare provider, including physicians, nurses, and pharmacists are responsible for counseling patients to understand OCP \& IUD instructions.

Regarding source of information, the present results indicated that the primary source of women's knowledge was the health care team; studies were, done in Qatar [19], found that friends were the most common source of knowledge about family planning methods among the women, followed by physicians and relatives. Health workers, teachers, and husband were different sources of knowledge about family planning.

Regarding variables influencing knowledge regarding contraceptive, the present study proofed that age, education, parity and contraceptive use are the most common factors that actively contributed to knowledge level regarding contraceptives. The obtained results came in agreement with other studies that found that the significant determinants of contraceptives' use include women's age, knowledge, education, parity, and work.

\section{Conclusion \& Recommendation}

The first step to increase the awareness of Saudi women regarding Intrauterine devices (IUD) and Oral Contraceptive Pills (OCP) is to implement health education programs throughout different mass media, primary health care centers, and other resources available in the community, as the dispersion of accurate information is important to the continued used and growing acceptance of these useful methods.

We recommend that particular attention should be, placed on reaching younger women on adult education programs, and emphasis must be, placed on spreading practical information about family planning methods to increase reproductive health.

\section{References}

[1] Hatcher, R.; Trussel, J.; Nelson, A. L.; Cates, Jr. W; Stewart, F. H. and Kowal, D. (2008). Contraceptive technology (19th Ed.). New York; Arden Media, Inc.

[2] Alkema, L.; Kantorova, V.; Menozzi, C. and Biddlecom, A. (2013). National, regional, and global rates and trends in contraceptive prevalence and unmet need for family planning between 1990 and 2015: a systematic and comprehensive analysis. Lancet, 381: 1642-52.

[3] Hannaford PC, Iversen L, Macfarlane TV, Elliott AM, Angus
V and Amanda Jl. (2010). Mortality among contraceptive pill users: cohort evidence from Royal College of General Practitioners' Oral Contraception Study. BMJ, 340: c927.

[4] Szarewski, A.; Mansour, D.; Shulman, L. P. (2010). 50 years of 'The Pill': celebrating a golden anniversary. J Fam Plann Reprod Health Care, 36: 231-238.

[5] Shulman, L. P. (2013). Changing convention in combination oral contraceptives: estradiol and nomegestrol acetate in a monophasic 24/4 regimen. J Fam Plann Reprod Health Care, 39: 211-216.

[6] Crosby, R. A.; DiClemente, R. J.; Wingood, G. M.; Rose, E.; and D., Lang (2003). Correlates of unplanned and unwanted pregnancy among African-American female teens. Am J Prev Med, 25: 255- 258.

[7] D'Arcangues, C. (2007). Worldwide use of intrauterine devices for contraception. Contraception. 75 (6 Suppl): S2-7.

[8] De Bocanegra, H. T.; Chang, R.; Howell, M. and Darney, P. (2014). Interpregnancy intervals: impact of postpartum contraceptive effectiveness and coverage. Am J Obstet Gynecol, 210: 311. e1-8.

[9] Al-Turki, H. A. (2011). Contraception: Attitudes and Experiences of Saudi Arabian Women. Health Care for Women International, 32: 134-139.

[10] Al-Shaikh, G. K.; Mayet, A. Y.; Alshaikh, M. K.; Hamad, A. F.; Mahmoud, M. ur A. and H. S., Aljadhey (2012). Knowledge, on adherence and safety of the oral contraceptive pill in Saudi women. Saudi Med J., 33(6): 665-671.

[11] Iftikhar, R.; Abdulrahman, B. and Al Khail, A. (2015). Knowledge about missed contraceptive pills among married women at King Abdulaziz University Hospital. Patient Preference and Adherence, 9: 401-411.

[12] Hall, K. S.; Westhoff, C. L. and P. M., Castaño (2013). The impact of an educational text message intervention on young urban women's knowledge of oral contraception. Contraception, 87(4): 449-454.

[13] Hall, K. S.; P. M., Castaño, C. L.; Stone, P. M. and Westhoff, C. (2010). Measuring Oral Contraceptive Knowledge: A Review of Research Findings and Limitations. Patient Educ Couns., 81(3): 388-394.

[14] Hodgson, E. J.; Collier, C.; Hayes, L.; Curry, L. and Fraenkel, L. (2013). Family planning and contraceptive decision-making by economically disadvantaged, African-American women. Contraception. 88(2): 289-296.

[15] Hatcher, R.; Trussel, J.; Nelson, A. L.; Cates, Jr. W; Stewart, F. H. and Kowal, D. (2008). Contraceptive technology (19th Ed.). New York; Arden Media, Inc.

[16] Al-Mansour, R.; Sabra, A. A. and A. S., Hafez (2012). Contraception: Knowledge, Attitude, and Practice with Special Emphasis on Contraceptive Pills among Saudi Women at Al-Khobar City, Eastern Saudi Arabia. The Egyptian Journal of Community Medicine, 30 (2): 1 - 13.

[17] Nobiling, Brandy; Drolet, Judy C. Exploring Trends in Intrauterine Device (IUD) Usage among Women in the United States: A Literature Review. Health Educator; Fall 2012, Vol. 44 Issue 2, p22. 
[18] Shahpoorian F., Kashanian M, Shakhan Z, Sheikh Ansari N. Contraceptive use in women under 20 years of age: A study in Iran. J Obstet Gynaecol. 2014 Oct; 34(7): 625-9. doi: 10.3109/01443615.2014.920312. Epub 2014 Jun 9.
[19] Arbab, A. A.; Bener, A. and Abdulmalik, M. (2011). Prevalence, awareness, and determinants of contraceptive use in Qatari women. Eastern Mediterranean Health Journal, 17 (1): $11-18$. 